\title{
Quality of Nurses' Performance Regarding Parenteral Nutrition at Neonatal Intensive Care Units
}

\author{
Noura Abdel-Fattah Mahmoud*, Faten Shafik Mahmoud**, Samah Mostafa \\ Khalaf** \\ *B.Sc. Nursing Science, **Pediatric Nursing Department, Benha University
}

\begin{abstract}
Background: Nurses play a crucial role at neonatal intensive care, as they are responsible for administering parenteral nutrition to critically ill neonates. Aim of the study was to assess quality of nurses' performance regarding parenteral nutrition at neonatal intensive care units. Settings: The study was conducted at neonatal. Intensive care units at Benha city in Benha University Hospital, Teaching Hospital and Specialized Pediatric Hospital. Design: A descriptive research design was utilized in the current study. Sample: A convenient sample of 70 nurses was participated in the current study. The tools of data collection were; a structured interviewing questionnaire and an observational checklist. Results: The present study revealed that more than three quarters of studied nurses had unsatisfactory level of total knowledge scores and more than two thirds of the studied nurses had incompetent in their total performance scores also, there was a statically significant relation between of the studied nurses' total knowledge scores and their personal data, there was a statically significant relation between of the studied nurses' total performance scores and their personal data. Conclusion: The present study revealed that there was statically significant relation between of the studied nurses' total knowledge and their personal data; there was statically significant relation between of the studied nurses' total performance scores and their personal data. Recommendation Developing training: programs recommended for the nurses working at regarding parenteral nutrition are neonatal intensive care units to improve their knowledge and performance.
\end{abstract}

Key words: Parenteral nutrition, Neonatal Intensive Care Units, Quality of nurses performance

Introduction

Neonatal period extends from birth through the first month of life and that is possibly the most tenuous in human's lifetime. During this time, the newborn undergoes physiological and anatomical changes as it adapts the new environment (Adewale, 2016).

The key success factors for health care quality improvement include; strong administrative and performance improvement leadership, effective oversight, involvement of expert quality improvement staff, physician involvement and accountability, active staff involvement. Moreover, effective use of data for decision making, and effective communication strategy should be achieved. The culture of the organization implementing the practice changes is also important (Shan et al., 2013). 


\section{Inclusion criteria:}

This study aimed to assess quality of nurses' performance regarding parenteral nutrition at neonatal intensive care units.

\section{The aim of this study is to:}

Assess quality of nurses' performance regarding parenteral nutrition at neonatal intensive care units through:

$\begin{array}{lccr}\text {-Assessing } & \text { nurses' } & \text { knowledge } \\ \text { regarding } & \text { parenteral } & & \begin{array}{r}\text { nutrition } \\ \text {-Assessing }\end{array} \\ \text { quality } & \text { of } & \begin{array}{r}\text { nurses' } \\ \text { parenteral }\end{array} \\ \text { performance } & \text { toward } & & \text { partion. } \\ \text { nutrition. } & & & \end{array}$

\section{Research questions:}

- Do nurses' knowledge regarding care of parenteral nutrition are satisfied?

- Do nurses have a competent performance regarding parenteral nutrition?

\section{Subjects and method}

\section{Study design:}

A descriptive design was used to fulfill the aim of this study

\section{Settings:}

This study was carried out at Neonatal Intensive Care Units of Benha University Hospital, Teaching Hospital and Specialized Pediatric Hospital at Benha city.

\section{Study Sample:}

\section{Sample type:}

A convenient sample of all the available: (70) nurses working at the previously mentioned settings with the following criteria
- Nurses working at neonatal intensive care units were included in the study

-Nurses had more than one year of experience Direct care provider (giving care to neonates)

\section{Tools of data collection:} Data were collected through the following tools:

Tool I: A structured interviewing questionnaire Sheets: It was designed by the researcher after reviewing related literatures and under supervision of supervisors. It was written in Arabic language and it composed of multiple choice questions and consists of six parts: Part I- Personal data of nurses, it consists of (10) questions such as; age, qualification level, years of experience, gender and attendance of training programs related to parenteral nutrition.

Part II- Knowledge of the studied nurses regarding quality and its related concepts, it consists of (11) questions such as; definition of quality, definition of quality in nursing care, quality standards, the level of quality in any therapeutic unit and assessment of nursing performance.

Part III - Knowledge of the studied nurses regarding parenteral nutrition, it consists of(19) questions such as; definition of parenteral nutrition, indication of parenteral nutrition, types of infusion devices,

complications of cannula and advantages of using parenteral nutrition.

Part IV- Knowledge of the studied nurses regarding infusion devices, it consists of (7) questions such as; importance of nursing training on this device before using it, regulation of volume to neonates by syringe pump and precautions to be take using when using pump device. 
Part V- Knowledge of the studied nurses regarding infection control related to neonates' feeding parenterally, it consists of(5) questions such as; actions to prevent infection, steps to give parenteral nutrition, important steps of infusion or solution preparation.

Part VI - Knowledge of the studied nurses regarding nursing care of neonates receiving parenteral nutrition, it consists of(14) questions such as; nursing care of umbilical catheter, time for calling physician, precautions of parenteral nutrition, time of changing intravenous device (alsalaust) and complications of inadequate provision of solution orinfusion. Total questions consist of 56 questions each one scored as the following:

Scoring system: Scoring system for each knowledge item (56questions)

\begin{tabular}{|l|r|}
\hline Scoringsystem & Score \\
\hline Correct\& complete & 2 \\
\hline Correct\&incomplete & 1 \\
\hline Incorrect & 0 \\
\hline
\end{tabular}

Scoring system for level of total knowledge.

\begin{tabular}{|c|c|}
\hline Scoringitem & Percent \% \\
\hline Satisfactory & $\geq 80 \%$ \\
\hline Unsatisfactory & $<80 \%$ \\
\hline
\end{tabular}

Tool II: An observational check list: it was adopted from Kalia \&walia, (2012 and Moran \& Leguna, ( 2015) and not modified by the researcher to assess performance of the studied nurses related to parenteral nutrition.
Scoring system for each performance.

\begin{tabular}{|l|l|}
\hline Scoringsystem & score \\
\hline Correctlydone & 2 \\
\hline Incorrectlydone & 1 \\
\hline Notdone & 0 \\
\hline
\end{tabular}

Each previous mentioned nursing performance was scored to calculate for total level as follow:

\begin{tabular}{|l|l|}
\hline Scoringitem & Percent \% \\
\hline Competent & $\geq 80 \%$ \\
\hline Incompetent & $<80 \%$ \\
\hline
\end{tabular}

\section{Field work:}

An official permission was obtained from the dean of Benha Faculty of Nursing and directed to hospitals' administrators of the previously mentioned settings with full explanation of the study purpose and methods of data collection.

- Tools validity and reliability: For validity assurance purpose, tools were submitted to jury of five experts in the field of pediatric nursing to be sure for questionnaire item (content validity). The reliability of tools was done to determine the extent to which items in the questionnaire were related each other by using Cronbach's co-efficiency alpha for the questionnaires (0.325).

\section{Ethical considerations:-}

The researcher explained the aim of the study to the nurses. They were informed that the study is harmless. The researcher secured that all the gathered data are confidential and are used for the research purpose only. The nurses were informed that they are optionally allowed either 
participate or not in the study and they have the right to withdraw at any time.

\section{Pilot study:}

A pilot study was carried out on $10 \%(n=7)$ of the expected sample size to test the applicability of study tools and to estimate the time needed to fill the questionnaire. The required modifications of tools were done by adding of some questions about nursing care of umbilical catheter or omission of some questions about parenteral nutrition, as; nurses' performance that lead to parenteral nutrition and method to prevent infection of parenteral nutrition according results of the pilot study.

\section{Data collection procedure:}

At first, the researcher assessed nurses' knowledge about (quality and parenteral nutrition) then the researcher observed performance about parenteral nutrition during their actual nursing care. The tools were filled individually by the researcher. Data were collected for a period of 6 months starting from first of November2015 to end of April 2016, along four days per week and six hour per day which divided two day in specialized pediatric hospital during morning shift because this hospital have the most number of sample and another two-hospital divided two days according time of procedures were observed. In detailed teaching hospital starting working in $7.30 \mathrm{am}$ finish 10.30 then university hospital starting procedure am observed in $11 \mathrm{am}$ to $1 \mathrm{pm}$. Approximatily12 hour in specialized hospital in week and six hours in week other hospital.

\section{Statistical analysis}

Data were coded and transformed into specially designed form to be suitable for computer data entry process. Data were manipulated and graphics were done by using SPSS version 20.
Results

As illustrated in table 1 nearly three quarters of the studied nurses working at Benha specialized hospital $(70.0 \%)$. In addition, slightly more than half of the studied nurses $(54.3 \%)$ had diploma of nursing. In addition, half of the studied nurses $(50.0 \%)$ had attendance training program related to parenteral nutrition.

As illustrated in table 2 the majority of the studied nurses had correct and complete answer $(80.0 \%, 98.6 \%, 95.7 \%)$ regarding the time of starting parenteral nutrition, the time consumed to regulate drop insertion to neonate and complications of cannula. Rather than three quarters $(71.4 \%, 75.7 \%)$ of the studied nurses correct and complete answer regarding calculation of infusion and the cannula sizes used for all neonates. The majority of had the studied nurses $(82.9 \%)$ had correct and complete answer regarding the size of cannula used according vein of neonate. More than three quarter of the studied nurse $(77.1 \%)$ had correct and incomplete answer regarding the colors of cannula used in neonates.

As illustrated in table 3 all of the studied nurses (100.0\%) had correct and complete answer regarding complications of take large amount of solution or infusion and release air from line of normal solution device or alsalaust. Rather than, the majority of the studied nurses $(87.1 \%)$ had correct and complete answer regarding time for calling physician and nursing care of umbilical catheter. the majority of the studied nurses (90.0\%) had correct and complete answer regarding precautions of parenteral nutrition Figure 1 illustrated that, more than three quarter $(78.6 \%)$ of the studied nurses had unsatisfactory total knowledge scores, while the rest $(21.4 \%)$ of them had satisfactory total knowledge scores.

Table 4 revealed that, the majority of the studied nurses $(98.6 \%, 82.9 \%, 82.9 \%)$ had incorrectly done regarding connect the 
I.V line to I.V access (cannula /scalp vein), wash hands, remove the bottle seal from the top, clean the top with spirit swab and holding the bottle upright, insert the drip set and air went into bottle. The majority of the studied nurses $(95,7 \%, 90.0 \%, 85.8 \%)$ had correctly done regarding open the clamp to let the fluid run, insert the I.V cannula into the vein at 15-30 angle and once it enters the vein, make it parallel with the skin and follow the course of the vein and immobilize with splint and . In addition, the majority of the studied nurses $(87.1 \%, 87.1 \%, 82.9 \%)$ had incorrectly done regarding connect the needle to the I.V tubing, clamp the tubing again and clean the area with aspirate swab. $(n=70)$.
Figure 2 revealed that more than two thirds $(64.3 \%)$ of the studied nurses had incompetent in their total performance scores regarding parenteral nutrition at neonatal intensive care units

Table 5 demonstrates that, there was a statistically significant relation between of the studied nurses' total performance scores and their personal data (age, qualification level, years of experience and training programe).

\begin{tabular}{|c|c|c|}
\hline Personaldata & Frequency & $\%$ \\
\hline \multicolumn{3}{|l|}{ Workingsetting } \\
\hline Benha university hospital & 12 & 17.1 \\
\hline Benha teaching hospital & 9 & 12.9 \\
\hline Benha specialized pediatric hospital & 49 & 70.0 \\
\hline \multicolumn{3}{|l|}{ Age in years } \\
\hline$\leq 20$ year & 13 & 18.6 \\
\hline $20<25$ year & 24 & 34.3 \\
\hline $25<30$ years & 20 & 28.5 \\
\hline$\geq 30$ years & 13 & 18.6 \\
\hline $\mathrm{X} \pm \mathrm{SD}$ & \multicolumn{2}{|c|}{$30.98 \pm 5.09$} \\
\hline \multicolumn{3}{|l|}{ Gender } \\
\hline Male & 4 & 5.7 \\
\hline Female & 66 & 94.3 \\
\hline \multicolumn{3}{|l|}{ Qualification level } \\
\hline Diploma of nursing & 38 & 54.3 \\
\hline Diploma of technical institute & 17 & 24.3 \\
\hline Bachelor degree in nursing & 13 & 18.6 \\
\hline Master degree in nursing & 2 & 2.9 \\
\hline \multicolumn{3}{|l|}{ Job } \\
\hline Nurse & 64 & 91.4 \\
\hline Head of department & 4 & 5.7 \\
\hline Unit supervisor & 2 & 2.9 \\
\hline \multicolumn{3}{|c|}{$\begin{array}{l}\text { Attendance of training programs related to } \\
\text { Parenteral nutrition }\end{array}$} \\
\hline Yes & 35 & 50.0 \\
\hline No & 35 & 50.0 \\
\hline
\end{tabular}


Noura Abdel-Fattah, Faten Shafik, \& Samah Mostafa

Table (2): Distribution of the studied nurses' knowledge regarding parenteral nutrition

\begin{tabular}{|c|c|c|c|c|c|c|}
\hline \multirow[t]{2}{*}{ Parenteralnutritionto neonates } & \multicolumn{2}{|c|}{$\begin{array}{r}\text { In } \\
\text { correct }\end{array}$} & \multicolumn{2}{|c|}{$\begin{array}{l}\text { Correct } \\
\& \\
\text { incompl } \\
\text { ete } \\
\text { answer }\end{array}$} & \multicolumn{2}{|c|}{$\begin{array}{l}\quad \text { Cor } \\
\text { rect\& } \\
\text { complete } \\
\text { answer }\end{array}$} \\
\hline & No & $\%$ & No & $\%$ & No & $\%$ \\
\hline Definition of parenteral nutrition in NICU & 13 & 18.6 & 45 & 64.3 & 12 & 17.1 \\
\hline Indications of parenteral nutrition & 6 & 8.6 & 44 & 62.9 & 20 & 28.6 \\
\hline Advantages of using parenteral nutrition & 8 & 11.4 & 41 & 58.6 & 21 & 30.0 \\
\hline Types of infusion & 12 & 17.1 & 29 & 41.4 & 29 & 41.4 \\
\hline Calculation of infusion & 7 & 10.0 & 13 & 18.6 & 50 & 71.4 \\
\hline Regulation of number of drops in minute & 0 & .0 & 51 & 72.9 & 19 & 27.1 \\
\hline The time of starting parenteral nutrition & 0 & .0 & 14 & 20.0 & 56 & 80.0 \\
\hline $\begin{array}{l}\text { The time consumed to } \\
\text { drop insertion to neonate }\end{array}$ & 0 & .0 & 1 & 1.4 & 69 & 98.6 \\
\hline The time of cannula insertion & 13 & 18.6 & 43 & 61.4 & 14 & 20.0 \\
\hline The route of infusion regulation & 28 & 40.0 & 1 & 1.4 & 41 & 58.6 \\
\hline $\begin{array}{l}\text { Calculation of number of drops for } \\
\text { insertion to neonates }\end{array}$ & 11 & 15.7 & 0 & .0 & 59 & 84.3 \\
\hline The cannula sizes used for all neonates & 17 & 24.3 & 0 & .0 & 53 & 75.7 \\
\hline $\begin{array}{l}\text { The size of cannula used according vein } \\
\text { of Neonate }\end{array}$ & 12 & 17.1 & 0 & .0 & 58 & 82.9 \\
\hline $\begin{array}{l}\text { The preferred sites to insert cannula in } \\
\text { Neonates }\end{array}$ & 8 & 11.4 & 15 & 21.4 & 47 & 67.1 \\
\hline $\begin{array}{l}\text { Syringe pump ensuring to regulate } \\
\text { infusion Accurately }\end{array}$ & 16 & 22.9 & 51 & 72.9 & 3 & 4.3 \\
\hline The colors of cannula used in neonates & 16 & 22.9 & 54 & 77.1 & 0 & .0 \\
\hline Types of infusion devices & 10 & 14.3 & 32 & 45.7 & 28 & 40.0 \\
\hline Complications of cannula & 0 & .0 & 3 & 4.3 & 67 & 95.7 \\
\hline
\end{tabular}


Table (3): Distribution of the studied nurses regarding their knowledge about nursing care of neonates receiving parenteral nutrition

\begin{tabular}{|l|c|c|c|c|c|c|}
\hline \multirow{2}{*}{$\begin{array}{l}\text { Nursing care of neonates } \\
\text { receiving parenteral } \\
\text { nutrition }\end{array}$} & \multicolumn{2}{c|}{ In correct } & \multicolumn{2}{c|}{$\begin{array}{c}\text { Correct\& } \\
\text { incomplete } \\
\text { answer }\end{array}$} & \multicolumn{2}{l|}{$\begin{array}{l}\text { Correct \& complete } \\
\text { answer }\end{array}$} \\
\cline { 2 - 7 } $\begin{array}{c}\text { Ensuring patent cannula or } \\
\text { catheter to neonate's feeding } \\
\text { parenteral nutrition }\end{array}$ & 8 & 11.4 & 25 & 35.7 & 37 & 52.9 \\
\hline $\begin{array}{c}\text { Change dressing on } \\
\text { centraline catheter }\end{array}$ & 1 & 1.4 & 39 & 55.7 & 30 & 42.9 \\
\hline $\begin{array}{c}\text { Change dressing on cannula } \\
\text { Fill half of drip chamber of }\end{array}$ & 16 & 22.9 & 24 & 34.3 & 30 & 42.9 \\
\hline $\begin{array}{c}\text { solution Device before } \\
\text { regulate solution }\end{array}$ & 2 & 2.9 & 67 & 95.7 & 1 & 1.4 \\
\hline $\begin{array}{l}\text { Release air from line of normal } \\
\text { solution device or alsalaust }\end{array}$ & 0.0 & 0.0 & 0.0 & 0.0 & 60 & 100.0 \\
\hline Precautions during infusion & 1 & 1.4 & 68 & 97.1 & 1 & 1.4 \\
\hline $\begin{array}{c}\text { Changing cannula every 3 } \\
\text { days regularity }\end{array}$ & 1 & 1.4 & 63 & 90.0 & 6 & 8.6 \\
\hline $\begin{array}{c}\text { Time of changing } \\
\text { intravenous device (alsalaust) }\end{array}$ & 0.0 & 0.0 & 38 & 54.3 & 32 & 45.7 \\
\hline $\begin{array}{c}\text { Complications of large } \\
\text { amount of solution or infusion }\end{array}$ & 0.0 & 0.0 & 0.0 & 0.0 & 70 & 100.0 \\
\hline $\begin{array}{l}\text { Complications of inadequate } \\
\text { provision of solution or infusion }\end{array}$ & 48 & 68.6 & 22 & 31.4 & 0.0 & 0.0 \\
\hline Time for calling physician & 2 & 2.9 & 7 & 10.0 & 61 & 87.1 \\
\hline Nursing care of umbilical catheter & 0.0 & 0.0 & 9 & 12.9 & 61 & 87.1 \\
\hline Precautions of parenteral nutrition & 0.0 & 0.0 & 7 & 10.0 & 63 & 90.0 \\
\hline
\end{tabular}

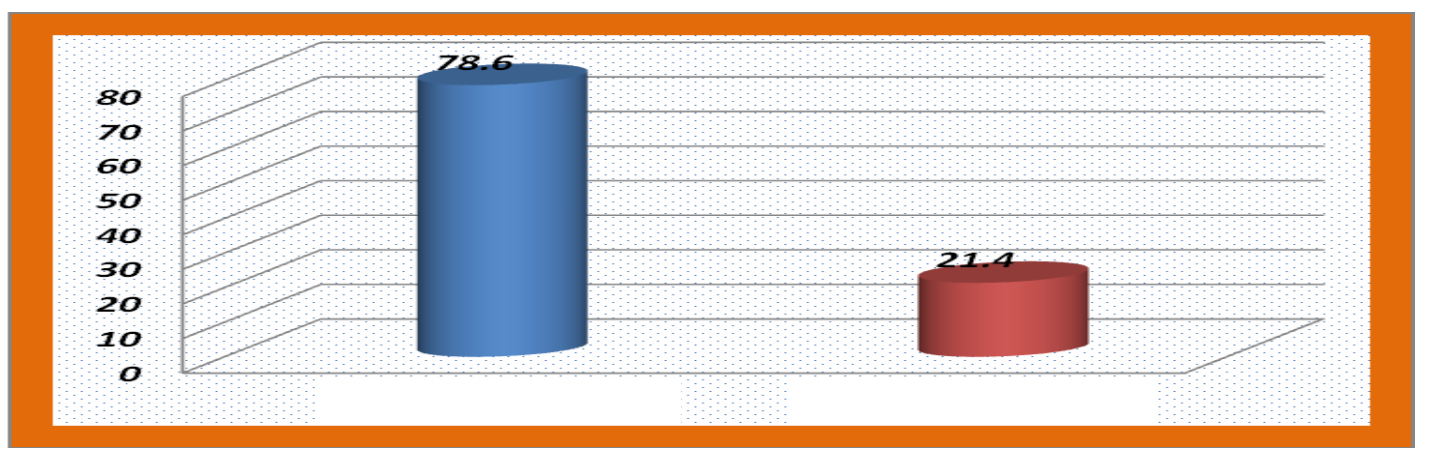

Figure (1): Percentage distribution of total knowledge scores of the studied nurses regarding parental nutrition at neonatal intensive care units. 
Table (4): Distribution of the studied nurses' performance regarding cannula insertion for parenteral nutrition $(n=70)$.

\begin{tabular}{|c|c|c|c|c|c|c|}
\hline \multirow[t]{2}{*}{$\begin{array}{l}\text { Nurses' performance regardingcannula } \\
\text { insertion for parenteralnutrition }\end{array}$} & \multicolumn{2}{|c|}{$\begin{array}{l}\text { Not } \\
\text { done }\end{array}$} & \multicolumn{2}{|c|}{$\begin{array}{c}\text { Incorrectly } \\
\text { done }\end{array}$} & \multicolumn{2}{|c|}{$\begin{array}{c}\text { Correctly } \\
\text { done }\end{array}$} \\
\hline & No & $\%$ & No & $\%$ & No & $\%$ \\
\hline Wash hands & 2 & 2.9 & 58 & 82.9 & 10 & 14.3 \\
\hline Remove thebottle seal from thetop & 2 & 2.9 & $\overline{58}$ & 82.9 & 10 & 14.3 \\
\hline Clean the top with spirit swab & 2 & 2.9 & 58 & 82.9 & 10 & 14.3 \\
\hline $\begin{array}{l}\text { Holdingthebottle upright,insert thedrip setand } \\
\text { air went into bottle }\end{array}$ & 2 & 2.9 & 58 & 82.9 & 10 & 14.3 \\
\hline $\begin{array}{l}\text { Close the clamp and hangthebottle on theI.V } \\
\text { stand about } 18-25 \text { "high }\end{array}$ & 1 & 1.4 & 18 & 25.7 & 51 & 72.9 \\
\hline Connect theneedle to theI.V tubing. & 0 & .0 & 61 & 87.1 & 9 & 12.9 \\
\hline $\begin{array}{l}\text { Open the clampand flush theI.V fluid through the } \\
\text { tubingand needle into kidneytrayuntil air } \\
\text { removed }\end{array}$ & 0 & .0 & 61 & 87.1 & 9 & 12.9 \\
\hline $\begin{array}{l}\text { Clamp the tubingagain,applyprotectivecap over } \\
\text { the needle }\end{array}$ & 0 & .0 & 61 & 87.1 & 9 & 12.9 \\
\hline Preparefew strips ofadhesive tapes & 58 & 82.9 & 0 & .0 & 12 & 17.1 \\
\hline $\begin{array}{l}\text { Site preparation: applytourniquets firmly } 6 \text { to } 8 \text { " } \\
\text { proximal to the site }\end{array}$ & 49 & 70.0 & 3 & 4.3 & 18 & 25.7 \\
\hline Clean the areawithaspiritswab. & 2 & 2.9 & 58 & 82.9 & 10 & 14.3 \\
\hline $\begin{array}{l}\text { Insert theI.Vcannula into the vein at } 15-30 \text { angle } \\
\text { and onceit enters thevein, makeit parallel } \\
\text { with the skin and follow thecourseof thevein }\end{array}$ & 0 & .0 & 7 & 10.0 & 63 & \\
\hline $\begin{array}{l}\text { When back flowof bloodoccur into theneedle and } \\
\text { its hub, insert theneedlefurtherinto the vein about } \\
\text { 3/4to } 1 \text { " }\end{array}$ & 0 & .0 & 42 & 60.0 & 28 & 40.0 \\
\hline Cap theI.V access toprevent bloodloss & 0 & .0 & 37 & 52.9 & 33 & 47.1 \\
\hline Releasethe tourniquet & 50 & 71.4 & 0 & .0 & 20 & 28.6 \\
\hline SecuretheI.V cannula with adhesive strips & 0 & .0 & 41 & 58.6 & 29 & 41.4 \\
\hline Immobilizewith splint & 5 & 7.1 & 5 & 7.1 & 60 & 85.8 \\
\hline $\begin{array}{l}\text { Connect theI.V line toI.V access (cannula/scalp } \\
\text { vein) }\end{array}$ & 0 & .0 & 69 & 98.6 & 1 & 1.4 \\
\hline Open the clamp to let thefluid run & 1 & 1.4 & 2 & 2.9 & 67 & 95.7 \\
\hline Set theflow rateand recheck it, onceor twice & 8 & 11.4 & 36 & 51.4 & 26 & 37.1 \\
\hline Record in nurses' note and intake - output chart & 28 & 40.0 & 3 & 4.3 & 39 & 55.7 \\
\hline Dissemble the articles & 0 & .0 & 42 & 60.0 & 28 & 40.0 \\
\hline
\end{tabular}

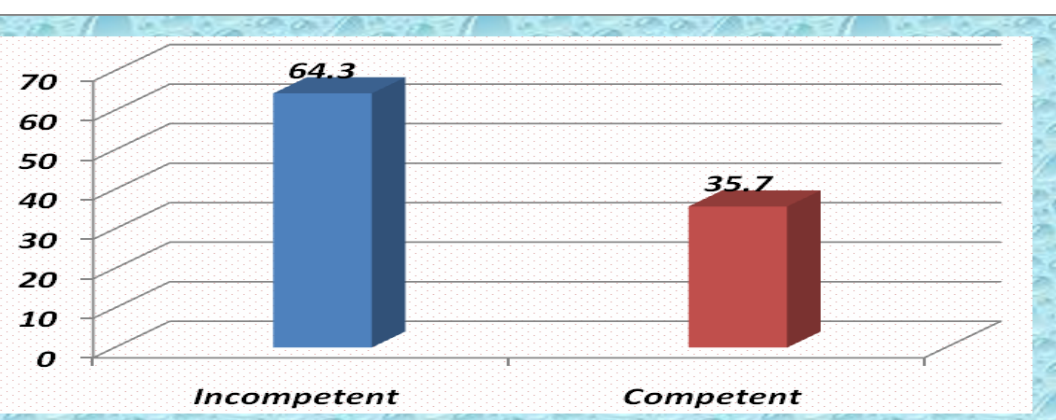

Figure (2): Percentage distribution of total performance scores of the studied nurses regarding parental nutrition at neonatal intensive care units. 
Table (5): Relation between of the studied nurses' total knowledge scores and their personal data $(n=70)$

\begin{tabular}{|c|c|c|c|c|c|c|}
\hline \multirow{3}{*}{ Items } & \multicolumn{4}{|c|}{ Total knowledge scores } & \multirow[b]{3}{*}{$\mathbf{X} 2$} & \multirow[b]{3}{*}{ Pvalue } \\
\hline & \multicolumn{2}{|c|}{ Unsatisfactory } & \multicolumn{2}{|c|}{ Satisfactory } & & \\
\hline & No & $\%$ & No & $\%$ & & \\
\hline Workingsetting & & & & & \multirow{4}{*}{14.48} & \multirow{4}{*}{$<0.001 *$} \\
\hline Benhauniversityhospital & 12 & $21.8 \%$ & 0 & $0.0 \%$ & & \\
\hline Benhateachinghospital & 3 & $5.5 \%$ & 6 & $40.0 \%$ & & \\
\hline Benhaspecializedpediatrichospital & 40 & $72.7 \%$ & 9 & $60.0 \%$ & & \\
\hline \multicolumn{5}{|l|}{ Age inyears } & \multirow{4}{*}{0.449} & \multirow{4}{*}{$<0.001$} \\
\hline$<20$ year & 10 & $18.2 \%$ & 3 & $20.0 \%$ & & \\
\hline $20<25$ year & 20 & $36.4 \%$ & 4 & $26.7 \%$ & & \\
\hline $25<30$ years & 16 & $28.2 \%$ & 4 & $26.7 \%$ & & \\
\hline$\geq 30$ & 9 & $16 \%$ & 4 & $26.7 \%$ & & \\
\hline \multicolumn{5}{|l|}{ Gender } & \multirow[b]{3}{*}{2.05} & \multirow[b]{3}{*}{$<0.001$} \\
\hline Male & 2 & $3.6 \%$ & 2 & $13.3 \%$ & & \\
\hline Female & 53 & $96.4 \%$ & 13 & $86.7 \%$ & & \\
\hline \multicolumn{5}{|l|}{ Qualificationlevel } & \multirow{5}{*}{2.58} & \multirow{5}{*}{$<0.001$} \\
\hline Diploma of nursing & 29 & $52.7 \%$ & 9 & $60.0 \%$ & & \\
\hline Diploma of technical institute & 13 & $23.6 \%$ & 4 & $26.7 \%$ & & \\
\hline Bachelor degree innursing & 12 & $21.8 \%$ & 1 & $6.7 \%$ & & \\
\hline Masterdegree $\quad$ innursing & 1 & $1.8 \%$ & 1 & $6.7 \%$ & & \\
\hline \multicolumn{5}{|l|}{ Job } & \multirow[b]{4}{*}{2.06} & \multirow{4}{*}{$<0.001$} \\
\hline Nurse & 50 & $90.9 \%$ & 14 & $93.3 \%$ & & \\
\hline Headofdepartment & 4 & $7.3 \%$ & 0 & $0.0 \%$ & & \\
\hline Unite supervisor & 1 & $1.8 \%$ & 1 & $6.7 \%$ & & \\
\hline \multicolumn{5}{|l|}{ Yearsof experience } & \multirow{5}{*}{2.56} & \multirow{5}{*}{$<0.001$} \\
\hline$\leq 3$ year & 7 & $12.7 \%$ & 3 & $20.0 \%$ & & \\
\hline $3<6$ year & 6 & $10.9 \%$ & 0 & $0.0 \%$ & & \\
\hline $6<9$ year & 11 & $20.0 \%$ & 2 & $13.3 \%$ & & \\
\hline$\geq 9$ year & 31 & $56.4 \%$ & 10 & $66.7 \%$ & & \\
\hline \multicolumn{5}{|l|}{$\begin{array}{l}\text { Attendance of training programs } \\
\text { related toparenteralnutrition }\end{array}$} & \multirow[b]{3}{*}{0.354} & \multirow[b]{3}{*}{$<0.001$} \\
\hline Yes & 32 & $58.2 \%$ & 10 & $66.7 \%$ & & \\
\hline No & 23 & $41.8 \%$ & 5 & $33.3 \%$ & & \\
\hline
\end{tabular}

\section{Discussion:}

Parenteral nutrition (PN) is indicated for initiation of nutritional support for premature and high-risk neonates, as it provides nutritional support when enteral intake is not possible or does not provide sufficient caloric requirements. The initial goal of PN is to minimize losses and preserve existing body stores; and progresses for provision of nutrition in order to promote growth and development (Ameri et al., 2016).

The present study was a descriptive study included a convenient sample of 70 nurses from Benha university hospital, specialized pediatric hospital and Benha teaching hospital. Worked at neonatal intensive care units aimed to assess quality of 
nurses' performance regarding parenteral nutrition at neonatal intensive care unit.

Regarding personal data of the studied nurses, the results of the present study revealed that, less than half of the studied nurses, were between $25<30$ years with mean age of $30.98 \pm 5.09$ year. This result was similar to the results of a study Ahmed,(2013) in a study entitled " Quality of Nursing Care for Neonates with Tracheoesophageal Fistula (Pre\&postoperative)", who found that, the age group of nurses were between 20>30years.

This finding disagreed with Mohamed, (2012) in a study entitled" Quality of Nursing Care for Neonates Undergoing Mechanical Ventilation at Benha City" who found that, less than half of the study nurses were between $20<25$ year. This may be indicated that the nursing care delivered to neonates received parenteral nutrition have high years of experience.

Concerning qualification level of the studied nurses, the present study viewed that, more than half of the studied nurses had diploma of nursing (secondary school), this may be due to the fact that secondary school in nursing provide the community with large number of graduate diploma nurses than other agencies such as faculties of nursing and institutes of nursing. These findings were supported by finding of Ahmed, (2013) in a study entitled "Quality of Nursing Care to Neonates Pre-Post Operation with Tracheotomy", who reported that, more than half of nurses had nursing diploma but Loutfy, (2014) in a study entitled "Quality of Nursing Care Provided for Preterm Infants Suffering from Respiratory DistressSyndrome", who found that, the majority of the studied nurses had bachelor of nursing.

The present study revealed that, more than half of the studied nurses had $\geq 9$ years of experience with a mean age $6.45 \pm 5.79$ years, which may be due to the nurses who provide care for parenteral nutrition in Benha hospitals were highly experienced nurses. This finding supported by Ahmed, (2013) who found that, more than half of the nurses attended training courses in NICU. Aemri et al., (2016) in a study entitled "Effect of a Comprehensive Total Parenteral Nutrition Training Program on Knowledge and Practice of Nurses in NICU", stated that the training courses plays an important role in enhancing and updating nurses' knowledge and performance beside improving the quality of care given to neonate receive parenteral nutrition regarding the nurse's attendance training courses for caring neonates in NICU.

Regarding nurses' knowledge regarding parenteral nutrition to neonates. The findings of the present study revealed that, more than two thirds of the studied nurses had correct and incomplete answers about definition of parenteral nutrition, less than two third of the nurses had correct and incomplete answer about indication of parenteral nutrition in neonates. This result may be due to training programmer not emphasis the point.

This finding was agreed with Ameri et al., (2016) who found that, the nurses had poor total knowledge including objectives, methods, prescriptive step, complications, prescription precautions, solutions to parenteral nutrition. In addition, Al-Rafay \& Al-Sharkawy, (2012) who emphasized that, NICUs' nurses play an important role in nutrition of premature children and infants. So, nurses should be knowledgeable about many treatment procedures and interventions such as; monitoring and caring the neonates during enteral or parenteral nutrition. Regarding nurses' knowledge about nursing care of neonates receiving parenteral nutrition. The findings of the present study found that, the majority of the studied nurses had correct and complete answers about precautions of parenteral nutrition and complications of large amount of infusion 
This result may be due to the most of nurses not attending any parenteral nutrition training programs. This finding was agreed with Ameri et al., (2016) in a study entitled "Effect of a Comprehensive Total Parenteral Nutrition Training Program on Knowledge and Practice of Nurses in NICU", who found that, follow relating parenteral nutrition administration The current study found that, the majority of the studied nurses had correct and complete answer about important steps of infusion or solution preparation. This may be due to most of training programs emphasized in infection control. This supported by Keogh et al., (2015) in a study entitled "Awareness of Health Workers of Total Parenteral Feeding in Neonatal Units". This study revealed that, each hospital follows different regulatory guidelines; hence location for PN preparation within the hospitals varies. PN was prepared by nursing staff in the ward, under aseptic technique during compounding and transferring as stated in the ASPEN guidelines. However, prepared TPN by a registered pharmacist under sterile conditions following ESPEN guidelines. Staff attitudes appeared to be driven by the need for optimal safety procedures. It has been reported that TPN mixtures made by nurses were more likely to be contaminated than commercial preparations The present study found that, more than two thirds of the studied nurses had incompetent of total performance scores. This result may be due to lack of attending programs about nursing care for neonates receiving parenteral nutrition. These findings in agreement with Shahin, (2012) in a study entitled " Nurses' Knowledge and Practices Regarding Enteral Nutrition at the Critical Care Department of Al- Manial University Hospital in Egypt: Impact of a Designed Instructional Program". Stated that, the studied nurses had incompetent andunsafe practices of nurses.

According to relation between of the studied nurses' total knowledge scores and their qualification level. This finding study reflected that, there was a positive relation between of the studied nurses' total knowledge scores and their qualification level $(p>0.01)$. This result may be due to more than half of the studied nurses had diploma of nursing. This finding was consistent with the finding of the study done by Loutfy, (2014) who found that, there was high statically significant relation between nurse's academic qualification and total nurses' knowledge scores $(p>0.01$ The current study's results revealed that, three quarters of the studied nurses had unsatisfactory total knowledge scores. This result may be nurses keep themselves from updating knowledge. This finding contracted with Daniel et al., (2013) in a study entitled" A study to Assess The Effectiveness of Structured Teaching Program on Care of Patient with Central Venous Access Device Among Staff Nurses in Selected Oncology Hospital of Bangalore", who stated that, more than two thirds of the studied nurses had good knowledge but this result not satisfied researcher who emphasize the nurses must have high knowledge scores.

\section{Conclusion}

Results of the present study concluded that; more than three quarters of studied nurses had unsatisfactory total knowledge scores and more than two thirds had incompetent total performance scores. Also, there was a statistically significant relation between of the studied nurses' total knowledge scores and their personal data. Moreover, there was a statistically significant positive relation between of the studied nurses' total performance scores and their personal data.

\section{Recommendations}

Based on the results of the current study, the following recommendations can be suggested: 


1. Developing periodical training
programs regarding
nutrition by faculty of nursing,
department of pediatric nursing for
the nurses working at neonatal
intensive care units to improve their
knowledge and performance.

2. Designing nursing protocol to ensure safe nursing practices.

3. Designing monitory system to continuously evaluate nurses' practical skills related to parenteral nutrition care in the neonatal intensive care units.

\section{Summary}

Nurses have an important responsibility in the care of neonates who are receiving $\mathrm{PN}$, including maintaining the catheter and delivery system, preparation and administration of PN solutions, replacing the dressings at the catheter insertion site and changing the infusion set at periodicintervals. Moreover, nursing practices, which reduce the risk factors for catheter related infection, include hand washing between neonate contacts, before and after touching the catheter or care delivery systems.

\section{Refernces:}

Adewale, H. (2016): Neonatal Period: Changes during the First Month of Life, 2nd edition, Educational Company,150153.

Ahmed, R. (2013): Quality of Nursing Care for Neonates with Tracheoesophageal Fistula (Pre\&Postoperative), Master degree, Faculty of Nursing, Benha University, Egypt.

\footnotetext{
Al-Rafay, S., \& Al-Sharkawy, S. (2012): Educational Outcomes Associated with Providing A comprehensive Guidelines Program about
}

Nursing Care to Preterm Neonates Receiving Parenteral Nutrition, Clinical Nursing Research Journal, 21(2): 142158.

Ameri, Z., Vafaee, A., Sadeghi,T., Mirlashari, Z., Nejad, D., \&Kalhor, F.(2016): Effect of A Comprehensive Total Parenteral Nutrition Training Program on Knowledge and Practice of Nurses in NICU, Canadian Center of Science and Education Journal, 8(10): 135.

Ayers, p., Adam, S., David, S., Boulleta, J., Neal, A \& Holocombe,b. (2014): A.S.P.E.N. Parenteral Nutrition Safety Consensus Recommendation, Journal of Parenteral and Enteral Nutrition, 38(3): 298-340.

Daniel, B., Nagaraju, B., Padmavathi,G.V., Bolouri, A., Zothanmawia, C., \& Sahar, S. (2013): The Effectiveness of Structured Teaching Programme on Care of Neonates Patient with Central Venous Access Device Among Staff Nurses in Selected Oncology Hospital of Bangalore, International Journal of Medicine and Medical Science Research1(1): 1-12.

Horber, J., \&Blesk, K. (2010): Collaborative Quality Improvement for Neonatal Intensive Care, Pediatric Journal, 10(1): 1-4.

Kalia, R., \&Walia, I. (2012): Pediatric Nursing Procedures, $1^{\text {st }}$ edition, Jaypee Brothers Publishers Company (P) LTD, 37-43.

Keogh, M., Ahmed, D., Abouazaid, c., \&Elmusharaf, K. (2015): Awareness of Health Workers of Total Parenteral Feeding in Neonatal Units, Bahrain Medical Bulletin Journal, 37(3): 1-6.

Loutfy A., (2014): Quality of Nursing Care Provided for Preterm Infants Suffering from Respiratory Distress 
Syndrome, Port Said scientific, Journal of Nursing August 2016-08-20, ISSN 2, $275-278$

Mohamed, A. (2012): Quality of Nursing Care for Neonate Undergoing Mechanical Ventilation at Benha city, Master Degree, Faculty of Nursing, Benha university, Egypt.
Moran, A., \&Leguna,T. (2015): Discharge Instructions: Total Parenteral Nutrition for Your Child, Fair View Health Journal, 8(16): 1-10.

Shahin, V., Warre, R., \&Klee, S. (2013): Quality Improvement Initiatives in Neonatal Intensive Care Units: Achievements and Challenges, Journal of Quality, ISSN

13 , 75 